\title{
Oxidative Stress and Epigenetic Instability in Human Hepatocarcinogenesis
}

\author{
Naoshi Nishida Masatoshi Kudo \\ Department of Gastroenterology and Hepatology, Kinki University School of Medicine, Osakasayama, Japan
}

\begin{abstract}
Key Words
DNA methylation - Oxidative stress · Reactive oxygen species - Tumor suppressor gene - Oncogene · Histone . Epigenetic instability $\cdot$ Hepatocellular carcinoma
\end{abstract}

\begin{abstract}
Hepatocellular carcinoma (HCC) is a major cause of cancer death, and its development is influenced by the status of inflammation and oxidative stress in the liver. Although oxidative stress might induce genetic changes and play a role in HCC development, many epigenetic alterations have also been reported in this type of tumor, suggesting the importance of epigenetic instability in hepatocarcinogenesis. Epigenetic instability results in 2 types of DNA alterations: hypermethylation of the promoter of tumor suppressor genes (TSGs), and hypomethylation of nonpromoter CpG, such as repetitive elements and satellite DNA. The former causes transcriptional inactivation of TSGs, while the latter reportedly induces chromosomal instability and an abnormal activation of oncogenes as well as mobile genetic elements. Oxidative stress could induce epigenetic instability and inactivate TSGs through the recruitment of the polycomb repressive complex to the promoter sequence carrying DNA damage induced by oxidation. Inflammatory cytokines from immune cells also reportedly induce expression of several histone and DNA modulators. On the other hand, DNA oxidation could lead to activation of DNA repair pathways and
\end{abstract}

affect the binding of methyl cytosine-binding protein to DNA, which could cause DNA hypomethylation. The decrease of the level of methyl group donors also contributes to the alteration in the methylation status. These mechanisms should act in concert and induce epigenetic instability, leading to HCC.

(c) 2013 S. Karger AG, Basel

\section{Introduction}

The accumulation of several genetic and epigenetic alterations is observed in hepatocellular carcinoma (HCC) cells, and these are considered to play a critical role in the alteration of cancer-related genes for the emergence of HCC [1]. The development of this tumor is closely associated with chronic inflammation as well as induction of oxidative stress [2]. For example, chronic infection with the hepatitis virus, the deposition of iron and copper, and steatosis of the liver are risk factors that can contribute to HCC emergence [3]; all of these factors also reportedly induce oxidative stress in hepatocytes. There is strong support to indicate that oxidative stress, possibly an important risk factor for HCC, can induce genetic as well as epigenetic alterations in cancer-related genes. This review focuses on the role of oxidative stress in the induction of epigenetic instability during the development of HCC.

\section{KARGER}

E-Mail karger@karger.com

www.karger.com/ddi
(C) 2013 S. Karger AG, Basel

0257-2753/13/0316-0447\$38.00/0
Naoshi Nishida, MD, PhD

Department of Gastroenterology and Hepatology, Kinki University School of Medicine 337-2 Ohno-higashi

Osakasayama, Osaka 589-8511 (Japan)

E-Mail naoshi@med.kindai.ac.jp 


\section{Oxidative Stress and Human}

Hepatocarcinogenesis

Several environmental factors, which are reportedly the risk of developing HCC, trigger the induction of oxidant-generating enzymes and increase the concentration of free radicals, leading to the activation of immune responses $[4,5]$. Free radicals include reactive oxygen species (ROS) such as alkoxy radicals and nitrogen species; among these, ROS could be produced endogenously and exogenously.

8-Oxo-7,8-dihydroguanine (8-oxodG) has been regarded as the most reliable marker of DNA damage induced by ROS [4]. Compared to healthy individuals, a high level of 8-oxodG was reported in several types of cancer [4], suggesting a close link between oxidative stress and the emergence of cancer. Furthermore, patients with chronic hepatitis showed an increase of 8-oxodG levels in hepatocytes, with an increased risk of HCC [6]. Nonalcoholic steatohepatitis, which is usually accompanied by diabetes mellitus and obesity, is another important example of chronic liver injury and the development of HCC though the increased production of endogenous ROS and 8-oxodG in hepatocytes [7, 8]. These findings indicate that oxidative stress and induction of ROS production plays an important role in human hepatocarcinogenesis.

The carcinogenic potential of oxidative stress can be attributable to the genotoxic effects of ROS, which are capable of causing base modifications and genetic instability. The formation of 8-oxodG is known to induce DNA base mutations such as $\mathrm{G}>\mathrm{T} / \mathrm{C}>\mathrm{A}$ transversions. Under normal conditions, the enzymes involved in the base excision repair mechanism, including DNA glycosylase, 8-oxoguanine glycosylase and MutY glycosylase homologue, excise 8-oxodG that is paired with cytosine and adenine $[4,9]$. However, an increase in oxidative stress could impair the repair mechanism, which could lead to the increase of mutations in oncogenes and tumor suppressor genes (TSGs) [9]. On the other hand, although $\mathrm{G}>\mathrm{T} / \mathrm{C}>\mathrm{A}$ transversions are common base substitutions reported in HCC, a recently published whole genome analysis suggests that the mutational spectrum of this type of tumor is heterogeneous [10]. This suggests that another mechanism of modification of cancer-related genes, such as the inactivation of TSGs through epigenetic pathways, could be induced by 8 -oxodG.

\section{Induction of Oxidative Stress and Hepatitis Virus Infection}

As mentioned above, an exposure to several environmental factors, including hepatitis B virus and hepatitis $\mathrm{C}$ virus (HCV) infection, alcohol, deposition of iron (hemochromatosis) and copper (Wilson's disease), obesity and type 2 diabetes (nonalcoholic fatty liver disease), is associated with chronic liver damage; these factors could induce oxidative stress in hepatocytes and cause the emergence of HCC. Here, we mainly focus on the oxidative stress induced by chronic viral hepatitis.

There is an established connection between chronic infection with the hepatitis virus and oxidative stress. Infection with hepatitis B virus has been reported to trigger several cellular pathways that lead to the generation of oxygen/nitrogen-reactive species. It could cause an increase of ROS and 8-oxodG production, and significant changes in intracellular levels of antioxidant enzymes and glutathione (GSH), with an impairment of the GSH redox cycle [11-13]. In a case of chronic hepatitis $C$, increased ROS production and the reduced expression and activity of the repair enzyme NEIL1 glycosylase was reported [14]. In patients with chronic hepatitis C and HCC, an increased level of 8-oxodG was positively associated with the degree of inflammation. Additionally, the cumulative disease-free survival after curative resection of HCC was shorter in HCC patients with a high percentage of 8-oxodG-positive hepatocytes [15]. Chronic HCV infection is also associated with the induction of endoplasmic reticulum (ER) stress [16-18]. The HCV-derived protein NS5A reportedly induces ER stress with the subsequent release of $\mathrm{Ca}^{2+}$ from the ER, which leads to a mitochondrial $\mathrm{Ca}^{2+}$ uptake and the generation of ROS in mitochondria [19]. An examination of HCV core transgenic mice revealed an accumulation of ROS that was associated with the emergence of HCC [20]. Another report found that the interaction of the HCV core protein with mitochondria, accompanied by ROS production and reduced GSH activity, was observed in HCV transgenic mice [21]. A transient expression of NS5A resulted in an alteration of intracellular $\mathrm{Ca}^{2+}$ levels, leading to oxidative stress and activation of the STAT3 and NF- $\kappa$ B signaling pathways [22].

Iron deposition also induces oxidative stress through the Fenton reaction [23]. Excess amounts of iron deposits are frequently observed in the liver of individuals with a chronic hepatitis $\mathrm{C}$ infection, and an iron overload induces mitochondrial injury and increases the risk of developing HCC [24]. The removal of excess iron by phle- 
Fig. 1. A schematic representation of the mechanism of alteration of the methylation status under conditions of oxidative stress and inflammation (upper panel), and the alteration of the methylation status in cancer cells (lower panel). ROS induce the expression of the transcription factor Snail, which leads to the expression and recruitment of DNMTs and HDACs to the TSG promoters. The induction of ROS production also leads to the recruitment of the polycomb complex to the damaged chromatin. Inflammatory cytokines induce the transcription of DNMTs and HDACs. These events contribute to the emergence of an abnormal methylation of the TSG promoters. On the other hand, DNA repair pathways and AID activities affect 5-methyl cytosine and yield thymine. The thymine is replaced by an unmethylated cytosine through the base excision repair processes. 8-OxodG weakens the binding of MBP to DNA, leading to a global hypomethylation. The closed and open circles represent methylated and unmethylated CpGs, respectively.

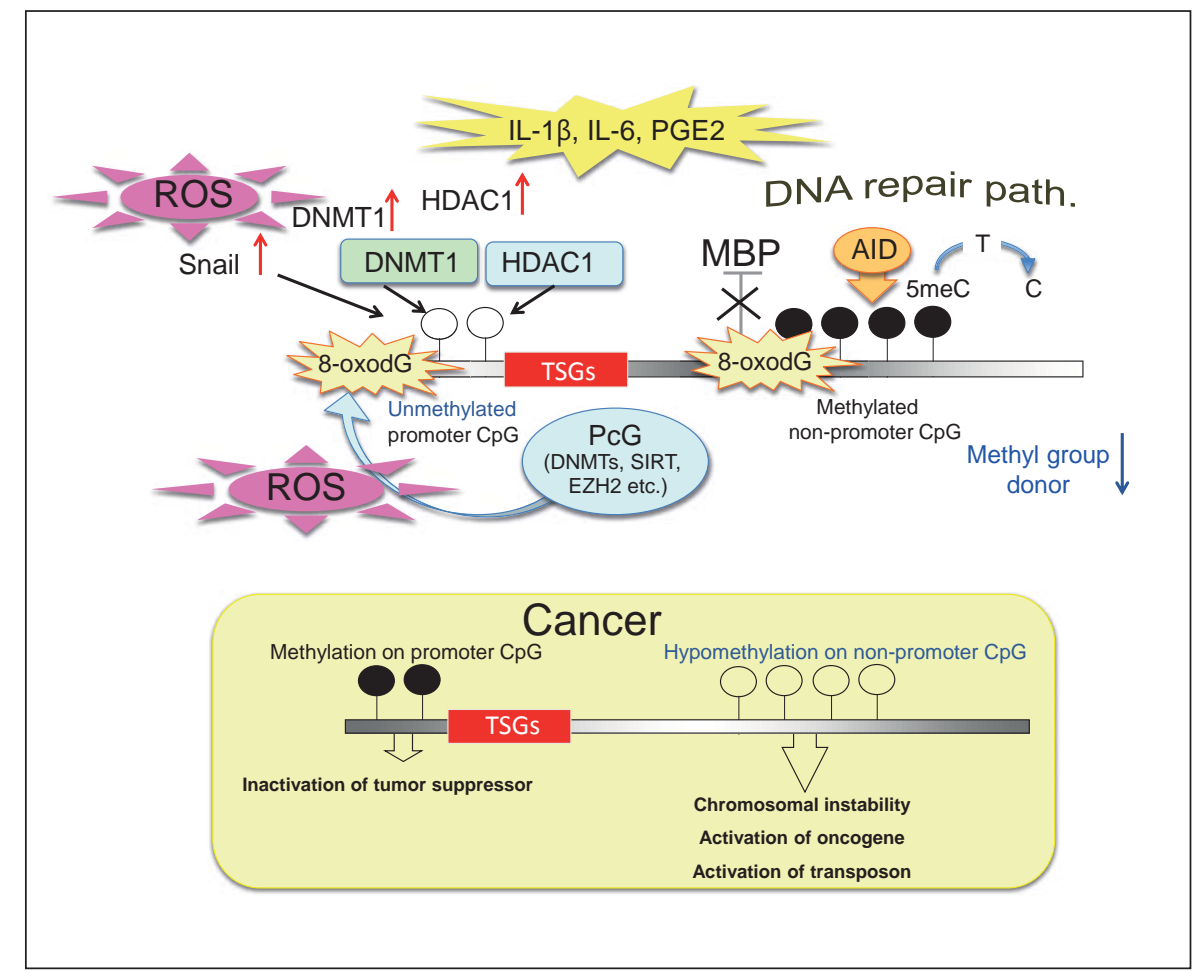

botomy attenuates hepatocyte injury in patients with HCV infection [25], and reduces the rate of HCC emergence [26]. Alcohol intake and steatosis also contribute to the development of oxidative stress in hepatocytes and increase the risk of HCC, especially in patients with chronic hepatitis $\mathrm{C}$. Acetaldehyde, the main metabolite of ethanol, elicits overproduction of ROS through acetaldehyde metabolism in mitochondria, which induces the apoptosis of hepatocytes and increases ROS formation in hepatic stellate cells [27]. In hepatic steatosis, the increase in $\beta$-oxidation in hepatocytes enhances electron delivery to the electron acceptors in the respiratory chain in mitochondria, which results in the generation of ROS due to the imbalance between a high input and a restricted outflow of electrons [18].

\section{Induction of Epigenetic Instability by Oxidative Stress}

DNA methylation usually takes place at the cytosine residues of the $\mathrm{CpG}$ dinucleotide. In normal cells, $\mathrm{CpG}$ islands in the promoters of transcriptionally active genes, such as TSGs, remain unmethylated, whereas CpG islands in nonpromoter regions (such as repetitive sequences) show dense methylation. Strikingly, global DNA hypomethylation and regional hypermethylation in TSG promoters are hallmarks of certain common cancer types, including HCC. It is also known that specific histone modifications, acetylation of histone $\mathrm{H} 3$ and $\mathrm{H} 4$, and trimethylation of lysine 4 of histone $\mathrm{H} 3$, are characteristics of active gene transcription. In contrast, dimethylation and trimethylation of $\mathrm{H} 3$ lysine 9 and trimethylation of $\mathrm{H} 3$ lysine 27 are associated with gene repression. Dimethylation of $\mathrm{H} 3$ lysine 9 is reportedly associated with DNA methylation in gene promoters [28]. Oxidative stress could induce an alteration in the methylation status of DNA, mainly by affecting the function and activity of the enzymes responsible for maintaining the epigenetic status, such as DNA methyltransferases (DNMTs), histone methylase and histone deacetylase (HDAC).

\section{Oxidative Stress and Regional Hypermethylation in the Promoters of TSGs}

Several reports suggest that oxidative stress affects the epigenetic machinery (fig. 1). It was reported that the induction of oxidative stress in the HCC cell line by hydrogen peroxide $\left(\mathrm{H}_{2} \mathrm{O}_{2}\right)$ resulted in hypermethylation of the promoter of the E-Cadherin gene by increasing Snail expression [29]. Snail was shown to induce DNA methyla- 
tion by recruiting HDAC1 and DNMT1. A correlation between ROS induction, E-Cadherin downregulation, Snail upregulation and E-Cadherin promoter methylation was also observed in human HCC samples [29]. Another study indicated that treatment of the human colorectal cancer cell line with $\mathrm{H}_{2} \mathrm{O}_{2}$ led to the upregulation of DNMT1 and HDCA, and increased the binding of DNMT1 to HDAC and DNMT1 binding to the promoter of a TSG such as the Runt domain transcription factor 3 (RUNX3). This effect was abolished by treatment with the ROS scavenger $\mathrm{N}$-acetylcysteine, suggesting that ROS silenced RUNX3 expression by an epigenetic mechanism and may be associated with the progression of colorectal cancer [30]. Furthermore, O'Hagan et al. [31] reported that oxidative stress results in the recruitment of the polycomb repressive complex to damaged chromatin. They showed that a colon cancer cell line treated with $\mathrm{H}_{2} \mathrm{O}_{2}$ showed the delocalization of the polycomb complex, which includes DNMT1, histone deacetylase (sirtuin-1), and histone methyltransferase (an enhancer of zeste homolog 2) from a non-CpG-rich region to CpG islandcontaining promoters carrying 8-oxodG [31]. These findings suggested that the oxidative stress induced by $\mathrm{H}_{2} \mathrm{O}_{2}$ could recruit histone modulators to the promoter sequence of active genes carrying DNA oxidation, and lead to the inactivation of TSGs through an epigenetic mechanism.

Additionally, several reports have suggested that inflammatory cytokines could play a role in the alteration of the epigenetic status. The expression level of inflammation-related molecules correlated with increased levels of DNA methylation in the gastric mucosa in cases of $H$. pylori-related gastric cancer [32]. Similar changes were also observed in the colonic mucosa in a model of dextran sulfate sodium-induced colon cancer [33]. These findings strongly support the idea that inflammation could induce aberrant DNA hypermethylation [34]. Several studies have been conducted to clarify the inflammatory signal that leads to DNA methylation. Interleukin (IL)-1 $\beta$ treatment of the insulinoma cell line increased the activity of DNMTs and resulted in the methylation of endogenous genes [35]. IL-6 also enhanced the promoter activity of DNMTs and increased transcription of this gene. It also decreased the levels of the microRNA that targets DNMT1 $[36,37]$. Treatment of cancer cell lines with prostaglandin E2 reportedly increased DNMT1 and DNMT3B expression and induced DNA methylation [38]. An in vitro model of IL-6-mediated chronic inflammation showed that IL-6 induced CpG methylation in the promoters of several TSGs and also induced a hypomethylation in in- terspersed nuclear element-1 (LINE-1) sequences in an oral squamous cell carcinoma line [39]. IL-6 has been reported to control DNA methylation through the IL6-mediated janus kinase (JAK)/transducers and activator of transcription (STAT) 3 pathway $[40,41]$. Therefore, inflammation could induce the epigenetic silencing and abnormal methylation in the promoters of TSGs through inflammation-mediated signaling pathways, which might play a role in carcinogenesis.

\section{Oxidative Stress and Global DNA Hypomethylation}

Global DNA hypomethylation has been identified as a common feature of various cancers, including HCC. Decrease of DNA methylation level in cancer cells generally takes place in repetitive DNA elements and is also observed in the gene body after the first exon. The demethylation of DNA in these regions may contribute to carcinogenesis through the following mechanisms. Firstly, demethylation of repetitive elements or satellite DNA might cause chromosomal instability $[42,43]$. Secondly, hypomethylation at retroviral mobile repetitive elements could induce the transcriptional activation of transposition [44]. Thirdly, demethylation could activate oncogenes, which might play a role in carcinogenesis $[45,46]$.

Recently, activation-induced cytidine deaminase (AID) was shown to be involved in the active DNA demethylation that occurs during fetal development [47]. AID deaminates 5-methyl cytosine to yield thymine, and this thymine is subsequently removed and replaced by an unmethylated cytosine through the base excision repair processes, resulting in DNA demethylation. Moreover, AID reportedly targets the chromatin marked by the trimethylation of lysine 4 of histone 3 [48]. Another report also suggested that the activation of the DNA repair pathway also induces DNA demethylation, which might lead to a global DNA hypomethylation [49].

On the other hand, cancer is usually characterized by a hypoxic state because of the lack of blood supply caused by the rapid progression of tumor growth and the resulting structural changes $[50,51]$. It was found that hypoxia induced oxidative stress, with an increased production of ROS. Hypoxia-inducible factor-1a (HIF-1 $\alpha$ ) was frequently induced in cancer cells and the generation of ROS was positively correlated with the upregulation of HIF$1 \alpha$, VEGF and DNA oxidation [52]. Furthermore, HIF$1 \alpha$ has recently been shown to regulate epigenetic modulators such as lysine demethylases. HIF-1 $\alpha$ functionally associates with HDACs to regulate gene expression in response to hypoxia [53-55]. 
Oxidative stress has been shown to inhibit the binding of methyl-CpG binding protein (MBP) 2, a critical epigenetic regulator that recruits DNMTs and histone HDAC to DNA $[56,57]$. The formation of 8-oxodG was reportedly associated with the hypomethylation of the CpG site. In normal conditions, the N7 position of guanine acts as a hydrogen bond acceptor during the formation of the MBP-DNA complex. The oxidation converts guanine to 8-oxodG, which transforms the guanine at the N7 position from a hydrogen bond acceptor to a hydrogen donor. The replacement of guanine by 8-oxodG diminishes MBP binding when 8-oxodG is adjacent to the 5 -methyl-cytosine $[56,58,59]$. Furthermore, the oxidation product of 5-methyl-cytosine, hydroxymethyl cytosine, also decreases the binding affinity of MBPs, resulting in DNA hypomethylation [60]. Mice containing mutations in the superoxide dismutase 1 gene showed an increase in 8-oxodG levels in the liver, with the progression of global DNA hypomethylation [61]. The presence of 8-oxodG in CpG strongly inhibits the methylation of the adjacent cytosine. Therefore, it could be possible that the DNA adduct-mediated inhibition of DNA methylation results in a progressive global demethylation.

The increased demand for methyl groups, a decrease in the availability of methyl group donors such as S-adenosylmethionine (SAM), and an increase in the levels of the methylation inhibitor S-adenosylhomocysteine (SAH) could also contribute to the global hypomethylation that is implicated in HCC development. An increase in inflammation in the liver tissue with reduced SAH hydrolase (SAHH) activity, and increased liver $\mathrm{SAH}$, which could also cause global DNA hypomethylation [62], was observed in a mouse model of Wilson's disease. In this model, the methylation level was increased by copper chelation or by treatment with a methyl group donor. This suggested that Wilson's disease is a condition associated with an increased demand for methyl groups due to an increase in the levels of the methylation inhibitor $\mathrm{SAH}$, which is attributable to an inhibitory effect of copper on SAHH [62]. The association between oxidative stress and hypomethylation of LINE-1 sequences was reported in bladder cancer patients [63]. Under the oxidative stress, the resynthesis of GSH was increased in response to GSH depletion. As SAM is required in the production of homocysteine that is used in the synthesis of GSH, increased production of GSH leads to the decrease of SAM necessary for maintaining the DNA methylation and the emergence of global DNA hypomethylation [64].

\section{Conclusions}

In this review, we have summarized the links between oxidative stress and epigenetic alterations in human hepatocarcinogenesis. Although the precise underpinnings of these processes are still unclear, it is very likely that oxidative stress is an underlying cause of the epigenetic instability that contributes to the initiation and progression of HCC. Understanding these molecular events is attractive from a therapeutic standpoint because several agents that could modulate the epigenetic status are going to be available in the coming years. Therefore, knowledge of these events will help in the prevention and management of HCC.

\section{Acknowledgements}

This work was supported in part by Grant-in-Aid for Scientific Research (KAKENHI: 24590997) from the Japanese Society for the Promotion of Science (N. Nishida) and a grant from the Smoking Research Foundation (N. Nishida).

\section{Disclosure Statement}

The authors have no conflicts of interest to declare.

\section{References}

1 Nishida N, Goel A: Genetic and epigenetic signatures in human hepatocellular carcinoma: a systematic review. Curr Genomics 2011; 12:130-137.

-2 Stauffer JK, Scarzello AJ, Jiang Q, Wiltrout $\mathrm{RH}$ : Chronic inflammation, immune escape, and oncogenesis in the liver: a unique neighborhood for novel intersections. Hepatology 2012;56:1567-1574.

Oxidative Stress and Epigenetic Instability in HCC
Kim DY, Han K: Epidemiology and surveillance of hepatocellular carcinoma. Liver Cancer 2012;1:2-14.

4 Ziech D, Franco R, Pappa A, Panayiotidis MI: Reactive oxygen species (ROS)-induced genetic and epigenetic alterations in human carcinogenesis. Mutat Res 2011;711:167-173.

5 Murata M, Thanan R, Ma N, Kawanishi S: Role of nitrative and oxidative DNA damage in inflammation-related carcinogenesis. J Biomed Biotechnol 2012;2012:623019.

\footnotetext{
Kitada T, Seki S, Iwai S, Yamada T, Sakaguchi $\mathrm{H}$, Wakasa $\mathrm{K}$ : In situ detection of oxidative DNA damage, 8-hydroxydeoxyguanosine, in chronic human liver disease. J Hepatol 2001; 35:613-618.

7 Seki S, Kitada T, Yamada T, Sakaguchi H, Nakatani K, Wakasa K: In situ detection of lipid peroxidation and oxidative DNA damage in non-alcoholic fatty liver diseases. J Hepatol 2002;37:56-62.
} 
8 Tanaka S, Miyanishi K, Kobune M, Kawano Y, Hoki T, Kubo T, Hayashi T, Sato T, Sato Y, Takimoto R, Kato J: Increased hepatic oxidative DNA damage in patients with nonalcoholic steatohepatitis who develop hepatocellular carcinoma. J Gastroenterol 2013, E-pub ahead of print.

$\checkmark 9$ Beard WA, Batra VK, Wilson SH: DNA polymerase structure-based insight on the mutagenic properties of 8-oxoguanine. Mutat Res 2010;703:18-23.

10 Totoki Y, Tatsuno K, Yamamoto S, Arai Y, Hosoda F, Ishikawa S, Tsutsumi S, Sonoda K, Totsuka H, Shirakihara T, Sakamoto H, Wang L, Ojima H, Shimada K, Kosuge T, Okusaka T, Kato K, Kusuda J, Yoshida T, Aburatani H, Shibata T: High-resolution characterization of a hepatocellular carcinoma genome. Nat Genet 2011;43:464-469.

-11 Hagen TM, Huang S, Curnutte J, Fowler P, Martinez V, Wehr CM, Ames BN, Chisari FV: Extensive oxidative DNA damage in hepatocytes of transgenic mice with chronic active hepatitis destined to develop hepatocellular carcinoma. Proc Natl Acad Sci USA 1994;91: 12808-12812.

-12 Wang JH, Yun C, Kim S, Lee JH, Yoon G, Lee MO, Cho H: Reactive oxygen species modulates the intracellular level of HBx viral oncoprotein. Biochem Biophys Res Commun 2003;310:32-39.

13 Georgakilas AG, Mosley WG, Georgakila S, Ziech D, Panayiotidis MI: Viral-induced human carcinogenesis: an oxidative stress perspective. Mol Biosyst 2010;6:1162-1172.

-14 Pal S, Polyak SJ, Bano N, Qiu WC, Carithers RL, Shuhart M, Gretch DR, Das A: Hepatitis $C$ virus induces oxidative stress, DNA damage and modulates the DNA repair enzyme NEIL1. J Gastroenterol Hepatol 2010;25:627634.

15 Maki A, Kono H, Gupta M, Asakawa M, Suzuki T, Matsuda M, Fujii H, Rusyn I: Predictive power of biomarkers of oxidative stress and inflammation in patients with hepatitis $\mathrm{C}$ virus-associated hepatocellular carcinoma. Ann Surg Oncol 2007;14:1182-1190.

-16 Pavio N, Romano PR, Graczyk TM, Feinstone SM, Taylor DR: Protein synthesis and endoplasmic reticulum stress can be modulated by the hepatitis $\mathrm{C}$ virus envelope protein $\mathrm{E} 2$ through the eukaryotic initiation factor $2 \alpha$ kinase perk. J Virol 2003;77:3578-3585.

$\checkmark 17$ Tardif KD, Waris G, Siddiqui A: Hepatitis C virus, ER stress, and oxidative stress. Trends Microbiol 2005;13:159-163.

18 Sasaki Y: Does oxidative stress participate in the development of hepatocellular carcinoma? J Gastroenterol 2006;41:1135-1148.

19 Ma Y, Hendershot LM: The mammalian endoplasmic reticulum as a sensor for cellular stress. Cell Stress Chaperones 2002;7:222229.
20 Moriya K, Fujie H, Shintani Y, Yotsuyanagi $\mathrm{H}$, Tsutsumi $\mathrm{T}$, Ishibashi $\mathrm{K}$, Matsuura $\mathrm{Y}$, Kimura S, Miyamura T, Koike K: The core protein of hepatitis $\mathrm{C}$ virus induces hepatocellular carcinoma in transgenic mice. Nat Med 1998;4:1065-1067.

-21 Korenaga M, Wang T, Li Y, Showalter LA, Chan T, Sun J, Weinman SA: Hepatitis C virus core protein inhibits mitochondrial electron transport and increases reactive oxygen species (ROS) production. J Biol Chem 2005; 280:37481-37488.

22 Gong G, Waris G, Tanveer R, Siddiqui A: Human hepatitis $\mathrm{C}$ virus NS5A protein alters intracellular calcium levels, induces oxidative stress, and activates STAT-3 and NF- $\kappa$ B. Proc Natl Acad Sci USA 2001;98:9599-9604.

23 Lloyd DR, Phillips DH: Oxidative DNA damage mediated by copper(II), iron(II) and nickel(II) fenton reactions: evidence for sitespecific mechanisms in the formation of double-strand breaks, 8-hydroxydeoxyguanosine and putative intrastrand cross-links. Mutat Res 1999;424:23-36.

24 Furutani T, Hino K, Okuda M, Gondo T, Nishina S, Kitase A, Korenaga M, Xiao SY, Weinman SA, Lemon SM, Sakaida I, Okita K: Hepatic iron overload induces hepatocellular carcinoma in transgenic mice expressing the hepatitis C virus polyprotein. Gastroenterology 2006; 130:2087-2098.

25 Yano M, Hayashi H, Yoshioka K, Kohgo Y, Saito H, Niitsu Y, Kato J, Iino S, Yotsuyanagi H, Kobayashi Y, Kawamura K, Kakumu S, Kaito M, Ikoma J, Wakusawa S, Okanoue T, Sumida Y, Kimura F, Kajiwara E, Sata M, Ogata K: A significant reduction in serum alanine aminotransferase levels after 3-month iron reduction therapy for chronic hepatitis C: a multicenter, prospective, randomized, controlled trial in Japan. J Gastroenterol 2004;39:570-574.

26 Kato J, Kobune M, Nakamura T, Kuroiwa G, Takada K, Takimoto R, Sato Y, Fujikawa K, Takahashi M, Takayama T, Ikeda T, Niitsu Y Normalization of elevated hepatic 8-hydroxy$2^{\prime}$-deoxyguanosine levels in chronic hepatitis $\mathrm{C}$ patients by phlebotomy and low iron diet. Cancer Res 2001;61:8697-8702.

27 Novitskiy G, Traore K, Wang L, Trush MA, Mezey E: Effects of ethanol and acetaldehyde on reactive oxygen species production in rat hepatic stellate cells. Alcohol Clin Exp Res 2006;30:1429-1435.

28 You JS, Jones PA: Cancer genetics and epigenetics: two sides of the same coin? Cancer Cell 2012;22:9-20.

29 Lim SO, Gu JM, Kim MS, Kim HS, Park YN, Park CK, Cho JW, Park YM, Jung G: Epigenetic changes induced by reactive oxygen species in hepatocellular carcinoma: methylation of the E-cadherin promoter. Gastroenterology $2008 ; 135: 2128-2140$.

-30 Kang KA, Zhang R, Kim GY, Bae SC, Hyun JW: Epigenetic changes induced by oxidative stress in colorectal cancer cells: methylation of tumor suppressor RUNX3. Tumour Biol 2012;33:403-412.
31 O’Hagan HM, Wang W, Sen S, Destefano Shields C, Lee SS, Zhang YW, Clements EG, Cai Y, Van Neste L, Easwaran H, Casero RA, Sears CL, Baylin SB: Oxidative damage targets complexes containing DNA methyltransferases, SIRT1, and polycomb members to promoter CpG islands. Cancer Cell 2011;20:606619.

32 Maekita T, Nakazawa K, Mihara M, Nakajima T, Yanaoka K, Iguchi M, Arii K, Kaneda A, Tsukamoto T, Tatematsu M, Tamura G, Saito D, Sugimura T, Ichinose M, Ushijima T: High levels of aberrant DNA methylation in Helicobacter pylori-infected gastric mucosae and its possible association with gastric cancer risk. Clin Cancer Res 2006;12:989-995.

-33 Rosenberg DW, Giardina C, Tanaka T: Mouse models for the study of colon carcinogenesis. Carcinogenesis 2009;30:183-196.

34 Chiba T, Marusawa H, Ushijima T: Inflammation-associated cancer development in digestive organs: mechanisms and roles for genetic and epigenetic modulation. Gastroenterology 2012;143:550-563.

35 Hmadcha A, Bedoya FJ, Sobrino F, Pintado E: Methylation-dependent gene silencing induced by interleukin $1 \beta$ via nitric oxide production. J Exp Med 1999;190:1595-1604.

36 Hodge DR, Xiao W, Clausen PA, Heidecker G, Szyf M, Farrar WL: Interleukin-6 regulation of the human DNA methyltransferase (HDNMT) gene in human erythroleukemia cells. J Biol Chem 2001;276:39508-39511.

37 Braconi C, Huang N, Patel T: Microrna-dependent regulation of DNA methyltransferase-1 and tumor suppressor gene expression by interleukin- 6 in human malignant cholangiocytes. Hepatology 2010;51:881-890.

- 38 Xia D, Wang D, Kim SH, Katoh H, DuBois $\mathrm{RN}$ : Prostaglandin E2 promotes intestinal tumor growth via DNA methylation. Nature Med 2012;18:224-226.

39 Gasche JA, Hoffmann J, Boland CR, Goel A: Interleukin-6 promotes tumorigenesis by altering DNA methylation in oral cancer cells. Int J Cancer 2011;129:1053-1063.

40 To KF, Chan MW, Leung WK, Ng EK, Yu J, Bai AH, Lo AW, Chu SH, Tong JH, Lo KW, Sung JJ, Chan FK: Constitutional activation of IL-6-mediated JAK/STAT pathway through hypermethylation of SOCS-1 in human gastric cancer cell line. Br J Cancer 2004;91: 1335-1341.

41 Isomoto H, Mott JL, Kobayashi S, Werneburg NW, Bronk SF, Haan S, Gores GJ: Sustained IL-6/STAT-3 signaling in cholangiocarcinoma cells due to SOCS-3 epigenetic silencing. Gastroenterology 2007;132:384-396.

42 Wong NC, Wong LH, Quach JM, Canham P, Craig JM, Song JZ, Clark SJ, Choo KH: Permissive transcriptional activity at the centromere through pockets of DNA hypomethylation. PLoS Genet 2006;2:e17. 
43 Vera E, Canela A, Fraga MF, Esteller M, Blasco MA: Epigenetic regulation of telomeres in human cancer. Oncogene 2008;27:68176833.

-44 Howard G, Eiges R, Gaudet F, Jaenisch R, Eden A: Activation and transposition of endogenous retroviral elements in hypomethylation induced tumors in mice. Oncogene 2008;27:404-408.

45 Wainfan E, Poirier LA: Methyl groups in carcinogenesis: effects on DNA methylation and gene expression. Cancer Res 1992;52:2071s2077s.

-46 Stefanska B, Huang J, Bhattacharyya B, Suderman M, Hallett M, Han ZG, Szyf M: Definition of the landscape of promoter DNA hypomethylation in liver cancer. Cancer Res 2011; 71:5891-5903.

47 Cortellino S, Xu J, Sannai M, Moore R, Caretti E, Cigliano A, Le Coz M, Devarajan K, Wessels A, Soprano D, Abramowitz LK, Bartolomei MS, Rambow F, Bassi MR, Bruno T, Fanciulli M, Renner C, Klein-Szanto AJ, Matsumoto Y, Kobi D, Davidson I, Alberti C, Larue L, Bellacosa A: Thymine DNA glycosylase is essential for active DNA demethylation by linked deamination-base excision repair. Cell 2011;146:67-79.

48 Kato L, Begum NA, Burroughs AM, Doi T, Kawai J, Daub CO, Kawaguchi T, Matsuda F, Hayashizaki Y, Honjo T: Nonimmunoglobulin target loci of activation-induced cytidine deaminase (AID) share unique features with immunoglobulin genes. Proc Natl Acad Sci USA 2012;109:2479-2484.

49 Ma DK, Guo JU, Ming GL, Song H: DNA excision repair proteins and Gadd 45 as molecular players for active DNA demethylation. Cell Cycle 2009;8:1526-1531.
50 Goudar RK, Vlahovic G: Hypoxia, angiogenesis, and lung cancer. Curr Oncol Rep 2008; 10:277-282.

51 Lawless MW, O’Byrne KJ, Gray SG: Oxidative stress induced lung cancer and COPD: opportunities for epigenetic therapy. J Cell Mol Med 2009;13:2800-2821.

52 Pialoux V, Mounier R, Brown AD, Steinback CD, Rawling JM, Poulin MJ: Relationship between oxidative stress and HIF-1a mRNA during sustained hypoxia in humans. Free Radic Biol Med 2009;46:321-326.

53 Carrero P, Okamoto K, Coumailleau P, O'Brien S, Tanaka H, Poellinger L: Redoxregulated recruitment of the transcriptional coactivators CREB-binding protein and SRC1 to hypoxia-inducible factor $1 \alpha$. Mol Cell Biol 2000;20:402-415.

54 Ruas JL, Poellinger L, Pereira T: Functional analysis of hypoxia-inducible factor-1 $\alpha$ mediated transactivation: identification of amino acid residues critical for transcriptional activation and/or interaction with CREBbinding protein. J Biol Chem 2002;277: 38723-38730.

55 Xenaki G, Ontikatze T, Rajendran R, Stratford IJ, Dive C, Krstic-Demonacos M, Demonacos C: PCAF is an HIF- $1 \alpha$ cofactor that regulates p53 transcriptional activity in hypoxia. Oncogene 2008;27:5785-5796.

56 Valinluck V, Tsai HH, Rogstad DK, Burdzy A, Bird A, Sowers LC: Oxidative damage to methyl-CpG sequences inhibits the binding of the methyl-CpG binding domain (MBD) of methyl-CpG binding protein 2 (MeCP2). Nucleic Acids Res 2004;32:4100-4108.

57 Cortessis VK, Thomas DC, Levine AJ, Breton CV, Mack TM, Siegmund KD, Haile RW, Laird PW: Environmental epigenetics: prospects for studying epigenetic mediation of exposure-response relationships. Human Genet 2012;131:1565-1589.
58 Weitzman SA, Turk PW, Milkowski DH, Kozlowski K: Free radical adducts induce alterations in DNA cytosine methylation. Proc Natl Acad Sci USA 1994;91:1261-1264.

59 Turk PW, Laayoun A, Smith SS, Weitzman SA: DNA adduct 8-hydroxyl-2'-deoxyguanosine (8-hydroxyguanine) affects function of human DNA methyltransferase. Carcinogenesis 1995;16:1253-1255.

60 Donkena KV, Young CY, Tindall DJ: Oxidative stress and DNA methylation in prostate cancer. Obstet Gynecol Int 2010;2010:302051.

61 Bhusari SS, Dobosy JR, Fu V, Almassi N, Oberley T, Jarrard DF: Superoxide dismutase 1 knockdown induces oxidative stress and DNA methylation loss in the prostate. Epigenetics 2010;5:402-409.

62 Medici V, Shibata NM, Kharbanda KK, LaSalle JM, Woods R, Liu S, Engelberg JA, Devaraj S, Torok NJ, Jiang JX, Havel PJ, Lonnerdal B, Kim K, Halsted CH: Wilson's disease: changes in methionine metabolism and inflammation affect global DNA methylation in early liver disease. Hepatology 2013;57: 555-565.

63 Patchsung M, Boonla C, Amnattrakul P, Dissayabutra T, Mutirangura A, Tosukhowong $\mathrm{P}$ : Long interspersed nuclear element-1 hypomethylation and oxidative stress: correlation and bladder cancer diagnostic potential. PLoS One 2012;7:e37009.

64 Hitchler MJ, Domann FE: An epigenetic perspective on the free radical theory of development. Free Radic Biol Med 2007;43:10231036. 